\title{
10Be in Ice Cores and 14C in Tree Rings \\ Separation of Production and Climate Effects
}

\author{
Journal Article \\ Author(s): \\ Abreu, J.A.; Beer, J.; Steinhilber, F.; Christl, M.; Kubik, P.W. \\ Publication date: \\ 2013-06 \\ Permanent link: \\ https://doi.org/10.3929/ethz-b-000059458 \\ Rights / license: \\ In Copyright - Non-Commercial Use Permitted \\ Originally published in: \\ Space Science Reviews 176(1-4), https://doi.org/10.1007/s11214-011-9864-y
}




\title{
${ }^{10} \mathrm{Be}$ in Ice Cores and ${ }^{14} \mathrm{C}$ in Tree Rings: Separation of Production and Climate Effects
}

\author{
J.A. Abreu • J. Beer • F. Steinhilber • M. Christl • \\ P.W. Kubik
}

Received: 4 October 2010 / Accepted: 2 December 2011 / Published online: 3 January 2012

(C) Springer Science+Business Media B.V. 2011

\begin{abstract}
Cosmogenic radionuclides are more and more used in solar activity reconstructions. However, the cosmogenic radionuclide signal also contains a climate component. It is therefore crucial to eliminate the climate information to allow a better interpretation of the reconstructed solar activity indices. In this paper the method of principal components is applied to ${ }^{10} \mathrm{Be}$ data from two ice cores from opposite hemispheres as well as to ${ }^{14} \mathrm{C}$ data from tree rings. The analysis shows that these records are dominated by a common signal which explains about $80 \%$ of the variance on multi decadal to multi millennial time scales, reflecting their common production rate. The second and third components are significantly different for ${ }^{14} \mathrm{C}$ and ${ }^{10} \mathrm{Be}$. They are interpreted as system effects introduced by the transport of ${ }^{10} \mathrm{Be}$ and ${ }^{14} \mathrm{C}$ from the atmosphere where they are produced to the respective natural archives where they are stored. Principal component analysis improves significantly extraction of the production signal from the cosmogenic isotope data series, which is more appropriate for astrophysical and terrestrial studies.
\end{abstract}

Keywords Cosmic rays $\cdot$ Cosmogenic isotopes $\cdot$ Principal component analysis

\section{Introduction}

Cosmogenic radionuclides stored in natural archives such as ${ }^{10} \mathrm{Be}$ in ice cores and ${ }^{14} \mathrm{C}$ in tree rings have proven to be very useful in reconstructing past solar activity (Vonmoos et al.

Electronic supplementary material The online version of this article (doi:10.1007/s11214-011-9864-y) contains supplementary material, which is available to authorized users.

\author{
J.A. Abreu ( $\varangle)$ \\ ETH Zürich, Institut für Geophysik, Zurich, Switzerland \\ e-mail: jose.abreu@erdw.ethz.ch \\ J.A. Abreu · J. Beer · F. Steinhilber \\ EAWAG, Dübendorf, Switzerland \\ M. Christl · P.W. Kubik \\ Laboratory of Ion Beam Physics, ETH Zürich, Zurich, Switzerland
}


2006) and changes in the geomagnetic field intensity over many millennia (Muscheler et al. 2005). At present, cosmogenic radionuclides are the only proxy to significantly extend the record of solar activity which is restricted to the past 400 years of sunspot observations. They offer the unique opportunity not only to study the long-term history of solar activity (Solanki et al. 2004; Vonmoos et al. 2006; Steinhilber et al. 2008) and solar forcing (Steinhilber et al. 2009), but also to make predictions about future trends in solar variability (Abreu et al. 2008). However, the cosmogenic radionuclide signal contains also a climate component introduced by the transport of the radionuclides from the atmosphere where they are produced to the archive where they are stored. In order to make full use of the large potential of cosmogenic radionuclides the climate signal must be removed. Fortunately, while both nuclides are produced in a similar way, the response of the ${ }^{10} \mathrm{Be}$ and the ${ }^{14} \mathrm{C}$ systems to climate variations is very different by virtue of their different geochemical properties. ${ }^{14} \mathrm{C}$ enters the global carbon cycle, whereas ${ }^{10} \mathrm{Be}$ is removed within $1-2$ years from the atmosphere by precipitation. Thus, comparing both radionuclides makes it possible to distinguish between climate induced and production (solar/geomagnetic) variations. Since this idea was first put forward by Siegenthaler and Beer (1988), many authors have compared ${ }^{14} \mathrm{C}$ and ${ }^{10} \mathrm{Be}$ records and confirmed the presence of a dominant common signal of solar/geomagnetic origin as well as a less dominant climate component in cosmogenic radionuclides (e.g. Beer et al. 1988; Bard et al. 1997; Muscheler et al. 2004; Usoskin et al. 2009). In this article, we go an step further and propose to apply principal component analysis (PCA) to ${ }^{10} \mathrm{Be}$ from ice cores and ${ }^{14} \mathrm{C}$ from tree rings in order to decompose them into a production and a climate signal.

\section{$2{ }^{10}$ Be and ${ }^{14} \mathrm{C}$ Systems}

\subsection{The Production of Cosmogenic Radionuclides}

Cosmic rays are composed roughly of $90 \%$ protons, $9 \%$ helium nuclei, and $1 \%$ of heavier nuclei. When these highly energetic primary particles of galactic cosmic rays interact with atmospheric $\mathrm{N}$ and $\mathrm{O}$, a chain of secondary particles is generated which is responsible for the production of cosmogenic radionuclides. There are two main processes which modulate the production rate of cosmogenic radionuclides in the atmosphere: changes in solar activity and changes in the geomagnetic field intensity. Since ${ }^{10} \mathrm{Be}$ and ${ }^{14} \mathrm{C}$ are produced by the same nucleonic secondaries of the cosmic ray induced atmospheric cascade, therefore their production signals are very similar. However, this production signal is modified by climate induced effects on the transport from the atmosphere into the respective archives as discussed in the next section.

\section{$2.2{ }^{10} \mathrm{Be}$ and ${ }^{14} \mathrm{C}$ in the Climate System}

Figure 1 illustrates the similarities and differences between ${ }^{10} \mathrm{Be}$ and ${ }^{14} \mathrm{C}$ radionuclides in the Earth's system. After production, ${ }^{14} \mathrm{C}$ oxidizes to $\mathrm{CO}_{2}$ and enters in the carbon cycle. Within the carbon cycle, ${ }^{14} \mathrm{C}$ gets involved in exchange processes among the atmosphere, the biosphere and the ocean. Its atmospheric residence time of about 8 years regarding exchange with the ocean is long enough that it can be considered as globally well mixed (Siegenthaler et al. 1980). In contrast, ${ }^{10} \mathrm{Be}$ has an atmospheric residence time of 1 to 2 years. The fact that ${ }^{14} \mathrm{C}$ enters the carbon cycle constitutes a fundamental difference between the measured signal in tree rings and the ${ }^{10} \mathrm{Be}$ signal measured in ice cores. The carbon cycle acts like 
Fig. $1{ }^{10} \mathrm{Be}$ and ${ }^{14} \mathrm{C}$ in the Earth's system. Similarities: Both radionuclides are produced in the same way, modulated by changes in solar activity and geomagnetic field intensity. Differences: After production, ${ }^{10} \mathrm{Be}$ becomes attached to aerosols and is removed from the atmosphere after a mean residence time of 1 to 2 years, while ${ }^{14} \mathrm{C}$ enters the carbon cycle. Therefore, climate changes influence the two radionuclides differently
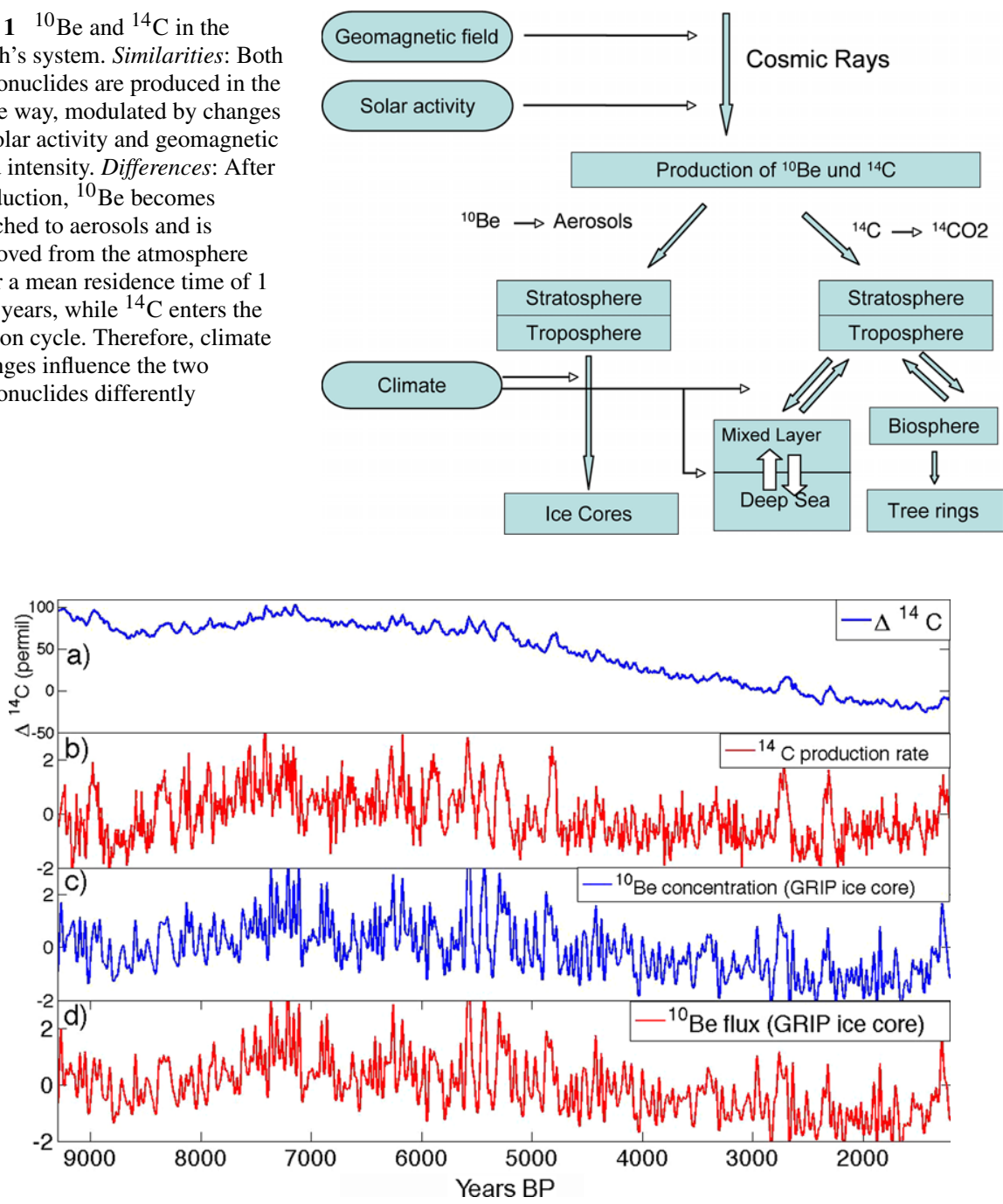

Fig. 2 a: $\Delta^{14} \mathrm{C}$ (per mil) as measured in tree rings. b: Standardized (i.e., subtracting the mean, then dividing by the standard deviation) of ${ }^{14} \mathrm{C}$ production rate calculated from $\Delta^{14} \mathrm{C}$ (per mil) by using a carbon cycle model. c: Standardized ${ }^{10} \mathrm{Be}$ concentrations (GRIP ice core) after being linearly interpolated to 1 year and low-pass filtered with a cutoff 40 years. d: Standardized ${ }^{10} \mathrm{Be}$ fluxes (GRIP ice core) after being linearly interpolated to 1 year and low-pass filtered with cutoff 40 years

a filter changing the original amplitude and phase of the ${ }^{14} \mathrm{C}$ production signal (Peristykh and Damon 2003). As a consequence, direct comparison between $\Delta^{14} \mathrm{C}$ measured in tree rings with ${ }^{10} \mathrm{Be}$ measured in ice cores is not informative. We must first remove the effect of the carbon cycle on ${ }^{14} \mathrm{C}$. Figure $2 \mathrm{a}$ shows $\Delta^{14} \mathrm{C}$ as measured in tree rings (Reimer et al. 2004). Figure $2 \mathrm{~b}$ shows the corresponding ${ }^{14} \mathrm{C}$ production rate calculated after applying the carbon cycle model by Oeschger et al. (1975). Figure $2 \mathrm{c}$ shows the ${ }^{10} \mathrm{Be}$ concentrations as measured in ice cores whereas Fig. $2 \mathrm{~d}$ shows the corresponding ${ }^{10} \mathrm{Be}$ flux. Comparison of the four panels shows clearly that ${ }^{10} \mathrm{Be}$ reflects changes in production rate much more 
directly than ${ }^{14} \mathrm{C}$. Furthermore, modelling shows that even a climate change from the present warm period with high solar activity to the Maunder minimum period with very low solar activity has only a small effect on the atmospheric transport and deposition processes of

${ }^{10} \mathrm{Be}$, confirming that production is the dominant factor (Heikkilä et al. 2008). Our two main working hypotheses are: (I) the ${ }^{10} \mathrm{Be}$ and ${ }^{14} \mathrm{C}$ records can be interpreted as being composed of a production signal, which is common to both radionuclides, and (II) a system signal, which is, most likely, not a common signal. Due to the different geochemical properties the combination of these two cosmogenic radionuclides in a PCA study provides a powerful tool to disentangle production and system effects.

\subsection{The Data}

In the present work we use ${ }^{10} \mathrm{Be}$ measured in EDML (Ice core drilled in the framework of the European Project for Ice Coring in Antartica (EPICA); Steinhilber et al. 2011 (submitted)) and GRIP (Greenland Ice Core Project; Yiou et al. 1997) ice cores and ${ }^{14} \mathrm{C}$ production derived from tree rings (INTCAL04; Reimer et al. 2004). The records employed in the analysis cover a common period of 8180 years from $1210 \mathrm{BP}$ to $9390 \mathrm{BP}$ (740 $\mathrm{AD}$ to $7440 \mathrm{BC}$ ). The averaged temporal resolution of the EDML time series is 4-5 years. The GRIP data have an average temporal resolution of 2-7 years. The ${ }^{10} \mathrm{Be}$ records were linearly interpolated to $1 \mathrm{y}$, resampled to $10 \mathrm{y}$, and $40 \mathrm{y}$ low-pass filtered. The ${ }^{10} \mathrm{Be}$ fluxes were calculated from ${ }^{10} \mathrm{Be}$ concentrations and the corresponding accumulation rates (Flux $=$ density of ice $*$ accumulation rate $*$ concentration). The ${ }^{14} \mathrm{C}$ record has a constant time resolution of 10 years and was $40 \mathrm{y}$ low-pass filtered.

Based on the previous discussion, we assume that the three data sets are composed of a production signal $P(t)$, as well as a system effect signal $S(t) . P(t)$ takes into account the modulation effect of the Sun and the geomagnetic field whereas $S(t)$ represents the effect that the climate exerts on the radionuclides including noise

$$
\begin{aligned}
{ }^{10} \mathrm{Be}_{\text {grip }}(t) & =P(t)+S_{1}(t), \\
{ }^{10} \mathrm{Be}_{\text {edml }}(t) & =P(t)+S_{2}(t), \\
{ }^{14} C(t) & =P(t)+S_{3}(t),
\end{aligned}
$$

where the subscripts indicate that the radionuclides are influenced differently by the climate. Additionally, the $S_{i}(t)$ terms may be written as

$$
S_{i}(t)=S_{i}[K(t)],
$$

where $K(t)$ stands for climate, an idealized variable which takes into account the temporal evolution of the climate. If the climate remains unchanged, then ${ }^{14} \mathrm{C}$ changes must be equal to ${ }^{10} \mathrm{Be}$ changes. As can be seen in Fig. 3 (only the interval 4400 to $5800 \mathrm{BP}$ is shown) the three curves are over all very similar, but there are some differences, which must be due to changes in the climate system. To separate the data into two components, we assume that $P(t)$ and $S_{i}(t)$ are uncorrelated. This assumption is supported by the following arguments: (1) the production does not depend on the climate and (2) although the climate components may correlate through solar modulation slightly with the production, climate change affects the ${ }^{14} \mathrm{C}$ and ${ }^{10} \mathrm{Be}$ systems very differently due to their different geochemical behaviors. 
Fig. 3 Standardized timeseries of ${ }^{10} \mathrm{Be}$ and ${ }^{14} \mathrm{C}$ data after being linearly interpolated to 1 year, resampled with 10 years, and low-pass filtered with a cutoff 40 years. Here we only depict the interval 4400 to $5800 \mathrm{BP}$ to show the structure of the data

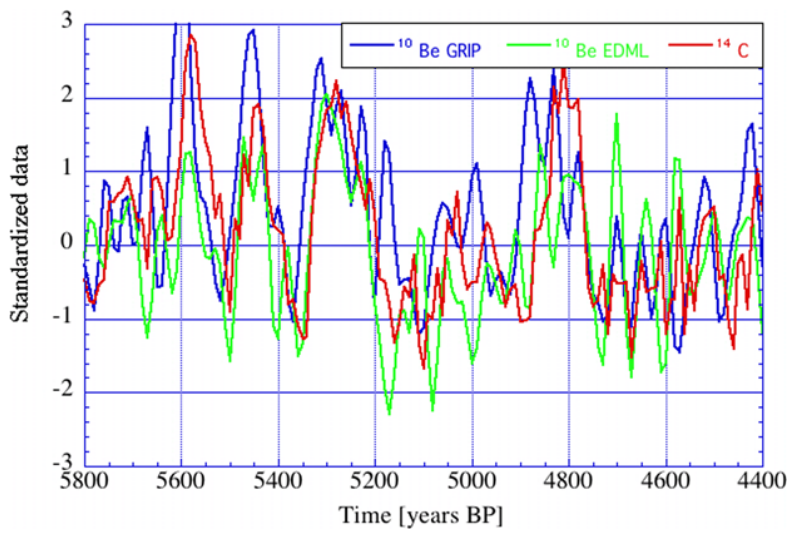

\section{Separation of Production and System Effects Using PCA}

Given the set of $p$ correlated time series $\left(X_{1}(t), X_{2}(t), X_{3}(t), \ldots, X_{i}(t), \ldots, X_{p}(t)\right)$ (in the present case $p=3$, two ${ }^{10} \mathrm{Be}$ records and one ${ }^{14} \mathrm{C}$ record), we can use PCA to find a new set of uncorrelated time series $C_{j}(t), j \leq p$ such as the original $p$ time series $X_{i}(\mathrm{t})$ can be decomposed as a linear combination of them, i.e.

$$
X_{i}(t)=\sum_{j} \alpha_{i, j} C_{j}(t)
$$

where

1. $\alpha_{i, j}=\sigma\left(X_{i}\right) R\left(C_{j}, X_{i}\right) / \lambda_{j}^{0.5}$ with $R\left(C_{j}, X_{i}\right)$ the correlation coefficient between the time series $C_{i}$ and $X_{j}$ and $\sigma$ is the standard deviation.

2. $\lambda_{j}$ are the eigenvalues of the covariance corresponding to the data matrix whose elements are $\operatorname{Cov}\left(X_{i}, X_{j}\right)$. They give the fraction of the total variance explained by the time series $C_{j}$.

The new time series $C_{j}$ are known as the principal components (Jolliffe 2002, see also the electronic supplementary material).

\section{Results}

Table 1 shows the calculated coefficients $\alpha_{i, j}$, i.e. the contribution of component $j$ to nuclide $i$ as expressed by (1). Additionally, the squared correlation coefficients along with the eigenvalues are shown. The eigenvalue corresponding to the first component explains $65 \%$ of the total variance whereas the second and third components are responsible for $22 \%$ and $14 \%$ of the total variance, respectively. Clearly, all the original data sets are well correlated with the first principal component supporting our hypothesis (I) that production dominates both radionuclides. Production changes are indeed responsible for most of the variance in the data. We attribute it to solar activity as well as to geomagnetic field variations. ${ }^{1}$ It is remarkable that the $\alpha_{2}$ coefficient corresponding to ${ }^{14} \mathrm{C}$ is significantly smaller than the corresponding $\alpha_{2}$ of the two ${ }^{10} \mathrm{Be}$ records. We note that

\footnotetext{
${ }^{1}$ The effect of the Earth's magnetic field, can be removed by taking into account paleorecords of the geomagnetic field and production calculations (Masarik and Beer 2009).
} 
Table $1 \alpha_{i, j}, R\left(C_{j}, X_{i}\right)^{2}$ and $\lambda_{i}$ before synchronization

\begin{tabular}{llll}
\hline & $\alpha_{1}$ & $\alpha_{2}$ & $\alpha_{3}$ \\
\hline${ }^{10} \mathrm{Be}_{\text {grip }}$ & 0.54 & 0.79 & 0.29 \\
${ }^{10} \mathrm{Be}_{\text {edml }}$ & 0.57 & -0.60 & 0.56 \\
${ }^{14} \mathrm{C}$ & 0.62 & -0.13 & -0.77 \\
\hline & $R^{2}$ & $R^{2}$ & $R^{2}$ \\
\hline${ }^{10} \mathrm{Be}_{\text {grip }}$ & 0.55 & 0.41 & 0.04 \\
${ }^{10} \mathrm{Be}_{\text {edml }}$ & 0.64 & 0.23 & 0.13 \\
${ }^{14} \mathrm{C}$ & 0.74 & 0.01 & 0.24 \\
\hline & $\lambda_{1}$ & $\lambda_{2}$ & $\lambda_{3}$ \\
\hline
\end{tabular}

Table $2 \alpha_{i, j}, R\left(C_{j}, X_{i}\right)^{2}$ and $\lambda_{i}$ after synchronization

\begin{tabular}{llll}
\hline & $\alpha_{1}$ & $\alpha_{2}$ & $\alpha_{3}$ \\
\hline${ }^{10} \mathrm{Be}_{\text {grip }}$ & 0.58 & 0.72 & 0.38 \\
${ }^{10} \mathrm{Be}$ edml & 0.58 & -0.70 & 0.42 \\
${ }^{14} \mathrm{C}$ & 0.57 & -0.02 & -0.82 \\
\hline & $R^{2}$ & $R^{2}$ & $R^{2}$ \\
\hline${ }^{10} \mathrm{Be}_{\text {grip }}$ & 0.77 & 0.18 & 0.06 \\
${ }^{10} \mathrm{Be}$ edml & 0.77 & 0.16 & 0.07 \\
${ }^{14} \mathrm{C}$ & 0.72 & 0.00 & 0.27 \\
\hline & $\lambda_{1}$ & $\lambda_{2}$ & $\lambda_{3}$ \\
\hline & $76 \%$ & $11 \%$ & $13 \%$ \\
\hline
\end{tabular}

1. the variance not explained by the first principal component for ${ }^{14} \mathrm{C}$ is explained only by the third component and

2. the variance not explained by the first principal component for both ${ }^{10} \mathrm{Be}$ records is mainly explained by the second component.

This confirms our initial hypothesis (II) that climate affects the ${ }^{14} \mathrm{C}$ and ${ }^{10} \mathrm{Be}$ systems differently. Hence, we attribute the second and third components to the climate effect on the ${ }^{14} \mathrm{C}$ and ${ }^{10} \mathrm{Be}$ systems, respectively.

The outcome of the PCA analysis depends critically on the accuracy of the time scales of the involved cosmogenic radionuclide records. While the time scale of ${ }^{14} \mathrm{C}$ is based on dendrochronology and therefore accurate to one year, the uncertainty of the time scales of the ice cores increases with age to a few decades. This is due to the fact that a perfect annual marker as in the case of trees is missing. In addition ice is flowing which leads to a decrease in the annual layer thickness with increasing depth. As a result of small time shifts, PCA interprets part of the common production changes as a different signal and assigns it to the second component. To test this effect, we slightly adjusted the two ${ }^{10} \mathrm{Be}$ time scales within the stated uncertainties to the ${ }^{14} \mathrm{C}$ time scale using wiggle matching (Ruth et al. 2007). The adjustments relative to the original time scales are smaller than $30 \mathrm{y}$ for EDML and 
smaller than $50 \mathrm{y}$ for GRIP. Now the first principal component explains $76 \%$ and the second component $11 \%$ of the total variance respectively (Table 2). However, the structure of the data remains relatively unchanged. The $\alpha_{2}$ coefficient for ${ }^{14} \mathrm{C}$ is one order of magnitude smaller than the corresponding values for ${ }^{10} \mathrm{Be}$. The third component is still the main nonproduction source of variability in ${ }^{14} \mathrm{C}$, whereas the second component is the main nonproduction source of variability for both ${ }^{10} \mathrm{Be}$ data sets. We notice that in both calculations the sign of $\alpha_{2}$ for GRIP and EDML are different. This is a mathematical consequence of the PCA method because of the limited number of ${ }^{10} \mathrm{Be}$ proxies used.

\section{Conclusions}

The method of PCA confirms that ${ }^{10} \mathrm{Be}$ and ${ }^{14} \mathrm{C}$ records which were all low-pass filtered with 40 years are dominated by a common signal which reflects the production rate and explains $76 \%$ of the variance on multi decadal to multi millennial time scales. The second and third components account for about $24 \%$ of the variance, which is significantly different for ${ }^{14} \mathrm{C}$ and ${ }^{10} \mathrm{Be}$. This can be explained as system effects introduced by the transport of the respective radionuclides from the atmosphere where they are produced to the archive where they are stored (tree rings in the case of ${ }^{14} \mathrm{C}$ and ice cores in the case of ${ }^{10} \mathrm{Be}$ ). The presence of such a high common variability is remarkable if we take into account that the ${ }^{10} \mathrm{Be}$ records are from different hemispheres, and that ${ }^{10} \mathrm{Be}$ and ${ }^{14} \mathrm{C}$ are characterized by completely different geochemical systems (compare panels (a) and (c) in Fig. 2). We have focused on the decomposition of cosmogenic radionuclides into production and system effects. Since cosmogenic radionuclides are the only tool to reconstruct past solar activity indices such as sunspots and total solar irradiance, it is crucial to eliminate the climate component. PCA is an adequate tool to achieve this aim.

Acknowledgements This work was financially supported by the Swiss National Science Foundation, and NCCR Climate-Swiss climate research.

\section{References}

J.A. Abreu, J. Beer, F. Steinhilber, S.M. Tobias, N.O. Weiss, Geophys. Res. Lett. 35, L20109 (2008)

E. Bard, G.M. Raisbeck, F. Yiou, J. Jouzel, Earth Planet. Sci. Lett. 150(3-4), 453-462 (1997)

J. Beer, U. Siegenthaler, H. Oeschger, G. Bonani, R.C. Finkel, Nature 331, 675-679 (1988)

U. Heikkilä, J. Beer, J. Feichter, Atmos. Chem. Phys. 8, 2797-2809 (2008)

I.T. Jolliffe, Principal Component Analysis, 2nd edn. Springer Series in Statistics (Springer, New York, 2002) J. Masarik, J. Beer, J. Geophys. Res. 114, D11103 (2009)

R. Muscheler, J. Beer, G. Wagner, C. Laj, C. Kissel, G.M. Raisbeck, F. Yiou, P.W. Kubik, Earth Planet. Sci. Lett. 219(3-4), 325-340 (2004)

R. Muscheler, J. Beer, P. Kubik, H.-A. Synal, Quat. Sci. Rev. 24(16-17), 1849-1860 (2005)

H. Oeschger, U. Siegenthaler, U. Schotterer, A. Gugelmann, Tellus 27(2), 168-192 (1975)

A.N. Peristykh, P.E. Damon, J. Geophys. Res. 108, 1003 (2003)

P.J. Reimer et al., Radiocarbon 46(3), 1029-1058 (2004)

U. Ruth et al., Clim. Past 3(3), 475-484 (2007)

U. Siegenthaler, M. Heimann, H. Oeschger, Radiocarbon 22(2), 177 (1980)

U. Siegenthaler, J. Beer, in Secular Solar and Geomagnetic Variations in the Last 10,000 Years, ed. by F.R. Stephenson, A.W. Wolfendale (Kluwer Academic, Dordrecht, 1988), p. 315

S.K. Solanki, I.G. Usoskin, B. Kromer, M. Schüssler, J. Beer, Nature 431, 1084-1087 (2004)

F. Steinhilber, J.A. Abreu, J. Beer, Astrophys. Space Sci. Trans. 4, 1-6 (2008)

F. Steinhilber, J. Beer, C. Fröhlich, Geophys. Res. Lett. 36, L19704 (2009)

F. Steinhilber, et al., 9400 years of cosmic radiation and solar activity from ice cores and tree rings. Proc. Natl. Acad. Sci. USA (2011, submitted)

I.G. Usoskin, K. Horiuchi, S. Solanki, G.A. Kovaltsov, E. Bard, J. Geophys. Res. 114, A03112 (2009)

M. Vonmoos, J. Beer, R. Muscheler, J. Geophys. Res. 111, A10105 (2006)

F. Yiou et al., J. Geophys. Res. 102(C12), 26783-26794 (1997) 